\title{
Effects of Sprayable and Granular Formulation of Insecticides on the Dehydrogenase Activity of Soil in Rice Ecosystem
}

\author{
Swagatika Misra* and Santosh Kumar Panda \\ Department of Entomology, OUAT, India \\ *Corresponding author
}

\section{A B S T R A C T}

Keywords

Sprayable and granular insecticides, Soil dehydrogenase activity (DHA), Rice ecosystem, Triphenyl tetrazolium chloride (TTC), Triphenyl formazan (TPF)

Article Info

Accepted:

18 November 2019 Available Online: 10 December 2019
Field and laboratory experiments were conducted to investigate twelve insecticides comprising granular and spray formulations of imidacloprid, cartap hydrochloride, fipronil, chlorantraniliprole along with carbofuran, phorate and monocrotophos as insecticidal checks for their effects on soil dehydrogenase activity in rice ecosystem during kharif 2015. Sprayable and granular insecticidal applications at 20 and 50 DAT demonstrated that granules in general showed a greater negative effect on soil microbial activity compared to their spray counterpart. Both the formulations of chlorantraniliprole and cartap with greater dehydrogenase activity of 395479 and 340- $675 \mu \mathrm{g}$ TPF/g soil respectively consistently favoured the microbial activity at 10 and 20 days after insecticidal application as compared to other test molecules. Carbofuran $3 \mathrm{G}$ was found to be the safest granule showing greater phytotonic effect to plants.

\section{Introduction}

Rice is grown in many regions across India and is the second leading producer (111.0 million tonnes) of rice in the entire world next to China (148.87 million tonnes) during 201718. In India, out of total food grain production of 277.49 million tonnes, rice contributes to 111.01 million tonnes (Ministry of Agriculture \& Farmer's welfare, 2017-18). Insecticidal application though considered as first line of defence against insect pests, has some adverse effect on non-target organisms including soil microbial activities which may affect several soil functions altering the soil fertility and influencing the growth and development of plants. Plants interacting with beneficial microbes can also benefit from increased tolerance to herbivory (Vannette and Hunter, 2009). Dehydrogenases play a significant role in the biological oxidation of soil organic matter by transferring hydrogen from organic substrates to inorganic acceptors (Zhang et al., 2010). Many specific dehydrogenases transfer hydrogen to either nicotinamide adenine 
dinucleotide or nicotinamide adenine dinucleotide phosphate (Subhani et al., 2001). Throughout mentioned co-enzymes hydrogen atoms are involved in the reductive processes of biosynthesis. Due to this fact, the overall DHA of a soil depends on the activities of various dehydrogenases, which are fundamental part of the enzyme system of all living microorganisms, like enzymes of the respiratory metabolism, the citrate cycle, and $\mathrm{N}$ metabolism (Subhani et al., 2001). Thus, DHA serves as an indicator of the microbiological redox-systems and could be considered a good and adequate measure of microbial oxidative activities in soil. Soil DHA is an indicator of soil quality and microbial activity and also is the most frequently used to determining the influence of various pollutants (like pesticides or excessive fertilization) on the microbiological quality of soils (Xie et al., 2009; Tejada et al., 2010). Despite the fact that pesticides are important tools in agriculture that help to minimize economic losses caused by weeds, insects and pathogens, they also are recognized as a source of potential adverse environmental impacts (Tejada et al., 2010). It is often assumed that less than $0.3 \%$ of the pesticide reaches its target pest; the remaining $99.7 \%$ is released to the environment, representing a potential hazard for non-target organisms (Muñoz-Leoz et al., 2011). Soil dehydrogenase activity is considered to be a valuable parameter for assessing the side effects of insecticide treatments on the soil microbial biomass.

A thorough understanding on effects of insecticides on non target organisms will therefore, enable the scientists in selection of a safer formulation of insecticide which fits into pest management strategies as well as has less adverse effect on microbial activity in soil. Hence the present investigation has been taken up to evaluate insecticides comprising of granular and spray formulations for their effects on soil dehydrogenase activity in rice ecosystem. Twelve insecticides viz. granular and spray formulations of imidacloprid, cartap hydrochloride, fipronil, chlorantraniliprole along with carbofuran, phorate and monocrotophos as insecticidal checks were taken up for assessment of their effects on dehydrogenase activity. The insecticides were applied at recommended doses and for the evaluation of dehydrogenase activity, soil samples were collected from rhizosphere of rice field. The soil samples were analysed in laboratory using the method developed by Casida et al., (1964). The detail of this study has been presented below.

\section{Materials and Methods}

Field experiment was taken up in rice field of Central Agricultural Research Farm of Odisha University of Agriculture and Technology, Bhubaneswar to investigate the adverse effects inflicted by sprayable and granular formulations of insecticides on the dehydrogenase activity of soil. The field experiment was laid out in randomized complete block design with popularly grown variety "Swarna" replicated thrice in sub plots of $20 \mathrm{~m}^{2}$ at a spacing of $20 \times 15 \mathrm{~cm}$. The treatments evaluated were given in Table 1 .

The test insecticides belonging to four different groups and with separate mode of actions were used primarily to observe their impact on soil dehydrogenase activity. The insecticides were applied twice at 25 and 50 DAT and soil sample from rhizosphere were collected at 10, and 20 days after application of insecticides and were subjected to laboratory analysis.

The most common laboratory procedure used for DHA determination was the method developed by Casida et al., (1964). According to this method, specific dyes such as the triphenyl tetrazolium chloride (TTC) that can 
specify the flow of electrons are useful indicators of electron transport system (ETS) activity. By the reduction of colorless, water soluble substrate (TTC) by dehydrogenases present in the soil environment, an insoluble product with red color (triphenylformazanTPF) is formed. TPF can be easily quantified calorimetrically at the range of visible light $(485 \mathrm{~nm})$. This test however, reflects positive answer only at neutral range of $\mathrm{pH}$ and in presence of calcium carbonate for buffering soil system. Briefly, if the red colors of soil samples prepared for spectrophotometer analyses are more intensive, the measured level of DHA is higher. Consequently, soil samples without red colors or those with light red colors are characterized by lower DHA values.

Soil samples were collected from 5 randomly different spots of the subplot while avoiding the soil from border rows. Then the soil was made up into a composite sample. $20 \mathrm{~g}$ of air dried soil is mixed thoroughly with $0.2 \mathrm{~g}$ of calcium carbonate $\left(\mathrm{CaCO}_{3}\right) .6 \mathrm{~g}$ of mixture was taken in a test tube. To each test tube, 1 $\mathrm{ml}$ of $3 \%$ aqueous solution of TTC and $2.5 \mathrm{ml}$ of distilled water was added. The mixture was then shaken well and plugged with a rubber stopper and incubated at $37^{\circ} \mathrm{C}$ for 24 hours in an incubator. Three replicates were maintained in each case. After $24 \mathrm{hrs}$ of incubation, $10 \mathrm{ml}$ of methanol was added to each test tube and mixed well. The resulting slurry was transferred on Whatman filter paper No.1 and extracted with successive aliquots of concentrated methanol. The soil was drained thoroughly until no colour could be extracted and then pooled with earlier extracts in a $100 \mathrm{ml}$ volumetric flask and then finally made up to the volume. The optical density of the filtrate was read at $485 \mathrm{~nm}$ in Spectrophotometer, using methanol extract as a blank. The activity was represented in terms of concentration of formazan, which was calculated by a standard curve of triphenyl formazan in methanol. Dehydrogenase activity per gram dry soil was expressed in terms of milligram formazan per gram dry soil per hour.

To prepare a standard curve, $10 \mathrm{ml}$ of TPF standard solution was diluted to $100 \mathrm{ml}$ using methanol (100microg of TPF/ml). Measured quantities of 5, 10, 15 and $20 \mathrm{ml}$ of aliquots were pipette in to $100 \mathrm{ml}$ volumetric flask, which makes it 500, 1000, 1500 and 2000 micro $\mathrm{g}$ of $\mathrm{TPF} / 100 \mathrm{ml}$. The volumes were made up using methanol and mixed thoroughly and then the intensity of red colour of TPF was measured using spectophotometer. The absorbance readings were plotted against the amount of TPF in $100 \mathrm{ml}$ standard solutions.

\section{Preparation of standards}

TTC: 3 grams of TTC was dissolved in about $80 \mathrm{ml}$ of water and the volume was made up to $100 \mathrm{ml}$.

TPF: $100 \mathrm{mg}$ of TPF was dissolved in about $80 \mathrm{ml}$ of methanol and the volume was made up to $100 \mathrm{ml}$ using methanol.

\section{Results and Discussion}

Soil DHA is an indicator of soil quality and microbial activity and also is most frequently used in determining the influence of various pollutants like pesticides or excessive fertilization on the microbiological quality of soils.

It is clearly visible from figure 1 that the dehydrogenase activity (DHA) is low at 10 days after application (DAA) compared to 20 DAS. Dehydrogenase activity in general is more in sprayable formulation indicating greater microbial activity in soil with spray treatments. 
Fig.1 Dehydrogenase activity of soil sample collected from rice field at 10 and 20 days after application (DAA) of various insecticides during kharif '2015

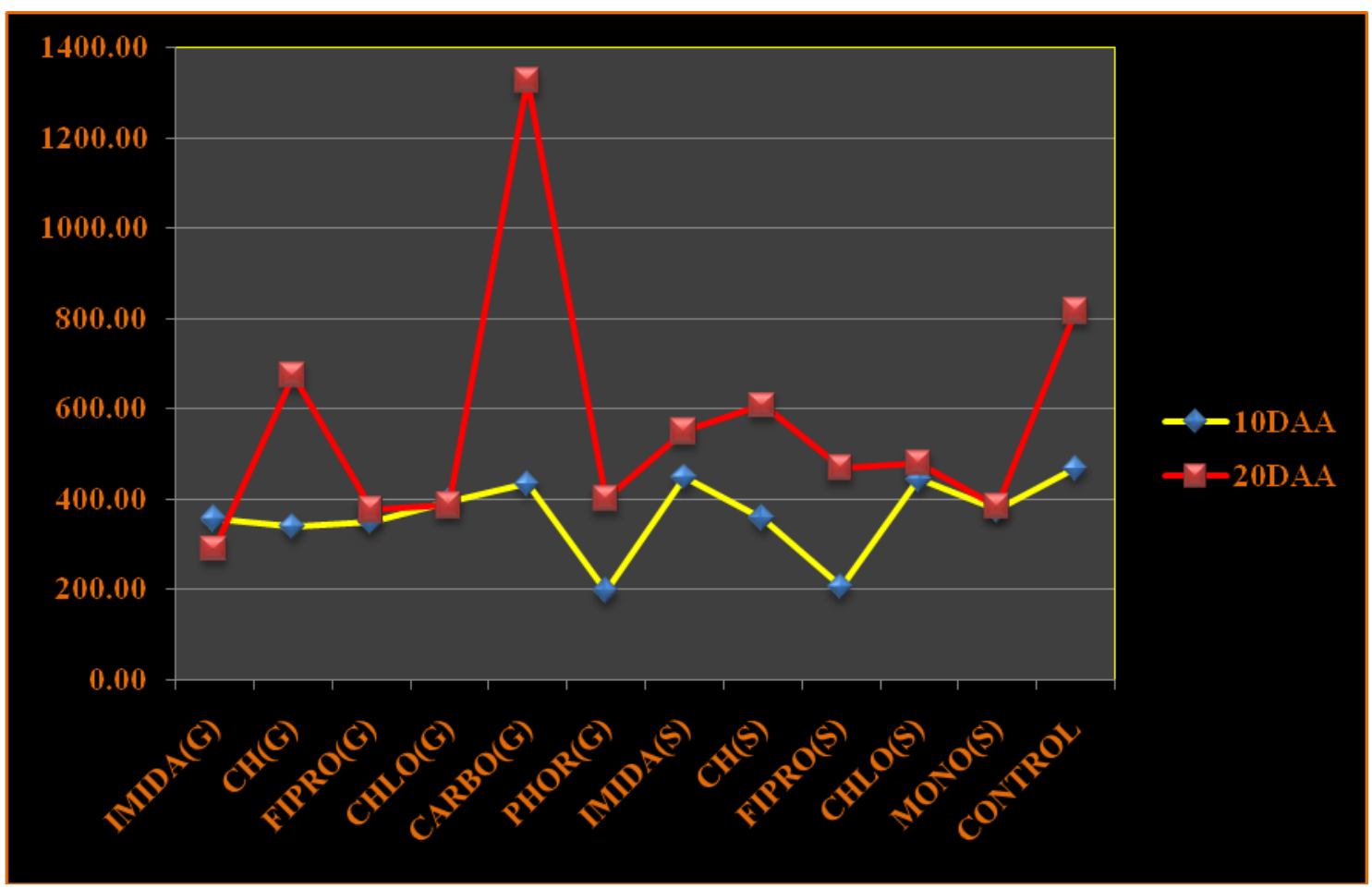

Table.1

\begin{tabular}{|c|l|c|}
\hline $\begin{array}{c}\text { Treatment } \\
\text { No. }\end{array}$ & \multicolumn{1}{|c|}{ Insecticide and formulation } & $\begin{array}{c}\text { Dose } \\
\text { (per ha) }\end{array}$ \\
\hline $\mathbf{T}_{\mathbf{1}}$ & Imidacloprid 0.3 G & $12.5 \mathrm{~kg}$ \\
\hline $\mathbf{T}_{\mathbf{2}}$ & Cartap 4 G & $20.0 \mathrm{~kg}$ \\
\hline $\mathbf{T}_{\mathbf{3}}$ & Fipronil 0.3 G & $12.5 \mathrm{~kg}$ \\
\hline $\mathbf{T}_{\mathbf{4}}$ & Chlorantraniliprole 0.4 G & $10.0 \mathrm{~kg}$ \\
\hline $\mathbf{T}_{\mathbf{5}}$ & Carbofuran 3 G(check) & $33.0 \mathrm{~kg}$ \\
\hline $\mathbf{T}_{\mathbf{6}}$ & Phorate 10 G(check) & $12.5 \mathrm{~kg}$ \\
\hline $\mathbf{T}_{\mathbf{7}}$ & Imidacloprid 17.8 SL & $150 \mathrm{ml}$ \\
\hline $\mathbf{T}_{\mathbf{8}}$ & Cartap hydrochloride 50SP & $750 \mathrm{~g}$ \\
\hline $\mathbf{T}_{\mathbf{9}}$ & Fipronil 5 SC & $1.0 \mathrm{lit}$ \\
\hline $\mathbf{T}_{\mathbf{1 0}}$ & Chlorantraniliprole $18.5 \mathrm{SC}$ & $150 \mathrm{ml}$ \\
\hline $\mathbf{T}_{\mathbf{1 1}}$ & Monocrotophos 36 SL (check) & $1.0 \mathrm{lit}$ \\
\hline $\mathbf{T}_{\mathbf{1 2}}$ & Untreated control & -- \\
\hline
\end{tabular}


Table.2 Dehydrogenase activity of soil sample collected from rice field receiving various insecticides during kharif ' 2015

\begin{tabular}{|c|c|c|c|c|c|c|c|c|c|c|}
\hline \multirow{2}{*}{$\begin{array}{c}\text { Treatment } \\
\text { no. }\end{array}$} & \multirow[t]{2}{*}{ Insecticides } & \multirow{2}{*}{$\begin{array}{c}\text { Dose of } \\
\text { commercial } \\
\text { product } \\
\text { (per ha) }\end{array}$} & \multirow{2}{*}{$\begin{array}{c}\text { micro g } \\
\text { TPF/g of } \\
\text { soil/24hrs } \\
\text { Rep A }\end{array}$} & \multicolumn{2}{|c|}{10 DAA } & \multirow{2}{*}{$\begin{array}{c}\text { micro g } \\
\text { TPF/g of } \\
\text { soil/24hrs } \\
\text { Rep A }\end{array}$} & \multicolumn{2}{|c|}{20 DAA } & \multirow{2}{*}{$\begin{array}{l}\text { Overall } \\
\text { Mean }\end{array}$} & \multirow{2}{*}{$\begin{array}{c}\text { Per cent } \\
\text { reduction } \\
\text { over control }\end{array}$} \\
\hline & & & & $\operatorname{Rep} B$ & Mean & & $\operatorname{Rep} B$ & Mean & & \\
\hline $\mathbf{T}_{1}$ & Imidacloprid $0.3 \mathrm{G}$ & $12.50 \mathrm{~kg}$ & 362.27 & 353.07 & 357.67 & 281.50 & 299.81 & 290.66 & 648.33 & 49.52 \\
\hline $\mathbf{T}_{2}$ & Cartap $4 \mathrm{G}$ & $20.00 \mathrm{~kg}$ & 334.35 & 345.00 & 339.68 & 679.81 & 669.81 & 674.81 & 1014.49 & 21.02 \\
\hline $\mathbf{T}_{\mathbf{3}}$ & Fipronil $0.3 \mathrm{G}$ & $20.00 \mathrm{~kg}$ & 355.96 & 344.03 & 350.00 & 351.75 & 398.24 & 375.00 & 724.99 & 43.63 \\
\hline $\mathbf{T}_{4}$ & Chlorantraniliprole $0.4 \mathrm{G}$ & $10.00 \mathrm{~kg}$ & 397.80 & 392.00 & 394.90 & 381.57 & 389.57 & 385.57 & 780.47 & 39.24 \\
\hline $\mathbf{T}_{5}$ & Carbofuran $3 \mathrm{G}$ & $33.00 \mathrm{~kg}$ & 418.07 & 450.34 & 434.21 & 1300.99 & 1352.50 & 1326.75 & 1760.95 & 37.1 \\
\hline $\mathbf{T}_{6}$ & Phorate $10 \mathrm{G}$ & $12.50 \mathrm{~kg}$ & 195.26 & 199.47 & 197.37 & 391.66 & 410.79 & 401.23 & 598.59 & 53.4 \\
\hline $\mathbf{T}_{7}$ & Imidacloprid 17.8 SL & $150 \mathrm{ml}$ & 426.31 & 472.36 & 449.34 & 548.24 & 550.24 & 549.24 & 998.58 & 22.26 \\
\hline $\mathbf{T}_{8}$ & Cartap hydrochloride $50 \mathrm{SP}$ & $750 \mathrm{~g}$ & 360.54 & 355.24 & 357.89 & 611.28 & 605.28 & 608.28 & 966.17 & 24.78 \\
\hline $\mathbf{T}_{9}$ & Fipronil 5 SC & $1000 \mathrm{ml}$ & 209.64 & 203.06 & 206.35 & 466.65 & 471.92 & 469.29 & 675.64 & 47.39 \\
\hline $\mathbf{T}_{10}$ & Chlorantraniliprole $18.5 \mathrm{SC}$ & $150 \mathrm{ml}$ & 433.33 & 456.13 & 444.73 & 475.92 & 481.92 & 478.92 & 923.65 & 28.09 \\
\hline $\mathbf{T}_{11}$ & Monocrotophos $36 \mathrm{SL}$ & $1000 \mathrm{ml}$ & 378.15 & 373.15 & 375.65 & 381.57 & 385.95 & 383.76 & 759.41 & 40.87 \\
\hline $\mathbf{T}_{12}$ & Untreated control & & 478.94 & 458.33 & 468.64 & 831.28 & 800.30 & 815.79 & 1284.43 & --- \\
\hline
\end{tabular}

*Rep - Replication 
Carbofuran 3G (check) was found to be the safest granule for microbial activity, which may have inhibited more beneficial microorganism, showing greater phytotonic effect to plants. At 10 DAA, chlorantraniliprole was found to be favourable for microbes. However, at 20 DAA, cartap was found safer to micro floral population followed by chlorantraniliprole.

Dehydrogenase is thought to be an indicator of overall microbial activity, because it occurs intracellular in all living microbial cells and is linked with microbial oxydoreduction process (Quilchano and Maranon, 2002; Stepniewska and Wolinska, 2005). Soil enzymes are strongly associated with microorganisms and soil enzymatic activity plays an important role in catalysing reactions indispensable in life processes of soil microorganisms. Thus, soil dehydrogenase activity is considered to be a valuable partner for assessing the side effects of pesticide treatments on soil microbial biomass.

Insecticides belonging to different groups and having different mode of action when used as granule and spray had shown their adverse impact on soil DHA which were significantly different in different treatments. The estimated DHA data presented in Table 2 clearly showed that almost all insecticides except granular fipronil resulted in a comparatively higher drop in DHA activities when used as granules (15.73 - $27.5 \%$ drop) compared to its spray formulations (4.11 $23.62 \%$ drop) at 10 days after second insecticide application. The reduction in DHA estimated at 20 DAA was more intense in granules with a record of $17.3-64.4 \%$ drop compared to that of $25.47-42.47 \%$ drop in spray treatments. This indicates higher degree of safety of sprayable formulation of insecticides compared to granules so far as soil microbial activity is concerned. Among the test insecticides it has been observed that imidacloprid had minimum drop in dehydrogenase activity with a record of 357.7-450 $\mu \mathrm{g}$ TPF/g soil as against $468.6 \mu \mathrm{g}$ $\mathrm{TPF} / \mathrm{g}$ soil in control at 10 days after insecticide application (DAA) indicating its favour to microbes, which of course is not reflected in the population estimates presented in Table 2. The same molecule however, exhibited very high level of drop in DHA 32.7-64.4\% over control at 20 DAA. On the other hand, chlorantraniliprole (395-479 $\mu \mathrm{g}$ $\mathrm{TPF} / \mathrm{g}$ soil) and cartap (340- $675 \mu \mathrm{g} \mathrm{TPF} / \mathrm{g}$ soil) consistently favoured the microbial activity at 10 and 20 days after insecticidal application compared to other test molecules. Carbofuran (check) typically encouraged the microbial activity and hence showed greater (1326.8 $\mu \mathrm{g} \mathrm{TPF} / \mathrm{g}$ soil) DHA than that of control $(815.8 \mu \mathrm{g} \mathrm{TPF} / \mathrm{g}$ soil) at 20 days after application (Figure 1).

The corresponding increase in microbial population in carbofuran treated plots is evident from population estimates presented in Table 2. Phorate (granular check) on the other hand, resulted in maximum harm to microbial activity with a drop in DHA by 57.8 $-95 \%$ over control. This finding supports the microbial population estimation to a greater extent which can be ascertained from Figure 1. According to Chendrayan and Sethunathan (1980) experimental conditions have a major influence on the activities of soil enzymes. Absence of any information on the persistence of the chemicals under the experimental conditions is an imperfection of many reports on side effects of pesticides. Clearly 20 days of monitoring microbial activities will be considerably shorter than the half lives of some of the pesticides tested in the study. For better understanding of impact of pesticides on microbes a thorough study on interaction between soil environment, soil enzymes (dehydrogenase specially) and soil microorganisms is strongly felt necessary. 


\section{Acknowledgement}

The authors are very much thankful to Dr. K. K. Rout, Dean, College of Agriculture and Dr. G. H. Santra, Former Professor, Department of Soil Science and Agricultural Chemistry, Odisha University of Agriculture and Technology for helping in successful research of dehydrogenase activity of soil in their laboratory.

\section{References}

Casida, L., Klein, D., and Santoro, T. 1964. Soil dehydrogenase activity. Soil Science, 98, pp. 371-376.

Chendrayan, K., and Sethunathan, N. 1980. Effects of $\mathrm{HCH}$, carbaryl, benomyl and atrazine on the dehydrogenase activity in a flooded soil. Bulletin of Environmental Contamination and Toxicology, 24:379-382.

Ministry of Agriculture \& Farmer's welfare, 2017-18.

Muñoz-Leoz, B., Ruiz-Romera, E., Antigüedad, I., and Garbisu, C. 2011. Tebuconazole application decreases soil microbial biomass and activity. Soil Biology \& Biochemistry, 43, pp. 21762183.

Quilchano, C., and Marañon, T. 2002. Dehydrogenase activity in Mediterranean forest soils. Biology \& Fertility of Soils, 35, pp. 102-107.

Stepniewska, Z., and Wolinska, A. 2005. Soil dehydrogenase activity in the presence of chromium(III) and (IV). International Agrophysics, 19, 79-83.

Subhani, A., Changyong, H., Zhengmiao, Y., Min, L., and El-ghamry, A. 2001. Impact of soil environment and agronomic practices on microbial/dehydrogenase enzyme activity in soil. A Review. Pakistan Journal of Biological Sciences, 4, pp. 333-338.

Tejada, M., Gomez, I., Garcia-Martinez, A., Osta, P., and Parado, J. 2010. Application of MCPA herbicide on soils amended with biostimulants: short-time effects on soil biological properties. Chemosphere, 80, pp. 1088-1094.

Vannette, R.L., and Hunter, M. D. 2009. Mycorrhizal fungi as mediators of defence against insect pests in agricultural systems. Agric for Entomol.11, 351-358.

Xie, W., Zhou, J., Wang, H., Chen, X., Lu, Z., Yu, J., and Chen, X. 2009. Shortterm effects of copper, cadmium and cypermethrin on dehydrogenase activity and microbial functional diversity in soils after long-term mineral or organic fertilization. Agriculture, Ecosystems \& Environment, 129: 450-456.

Zhang, N., He, X., Gao, Y., Li, Y., Wang, H., Ma, D., Zhang, R., and Yang, S. 2010. Pedogenic carbonate and soil dehydrogenase activity in response to soil organic matter in Artemisia ordosica community. Pedosphere, 20: 229-235.

\section{How to cite this article:}

Swagatika Misra and Santosh Kumar Panda. 2019. Effects of Sprayable and Granular Formulation of Insecticides on the Dehydrogenase Activity of Soil in Rice Ecosystem. Int.J.Curr.Microbiol.App.Sci. 8(12): 2458-2464. doi: https://doi.org/10.20546/ijcmas.2019.812.289 